Article

\title{
Structure of the PUB Domain from Ubiquitin Regulatory X Domain Protein 1 (UBXD1) and Its Interaction with the p97 AAA+ ATPase
}

\author{
Mike Blueggel ${ }^{1}(\mathbb{D})$, Johannes van den Boom ${ }^{2}$, Hemmo Meyer $^{2}$, Peter Bayer $^{1}(\mathbb{D})$ and \\ Christine Beuck 1,*iD \\ 1 University of Duisburg-Essen, Structural and Medicinal Biochemistry, Centre for Medical \\ Biotechnology (ZMB), 45117 Essen, Germany; mike.blueggel@uni-due.de (M.B.); \\ peter.bayer@uni-due.de (P.B.) \\ 2 University of Duisburg-Essen, Molecular Biology, 45117 Essen, Germany; \\ Johannes.van-den-boom@uni-due.de (J.v.d.B.); Hemmo.meyer@uni-due.de (H.M.) \\ * Correspondence: christine.beuck@uni-due.de; Tel.: +49-201-183-2929
}

Received: 7 November 2019; Accepted: 11 December 2019; Published: 14 December 2019

check for updates

\begin{abstract}
AAA+ ATPase p97/valosin-containing protein (VCP)/Cdc48 is a key player in various cellular stress responses in which it unfolds ubiquitinated proteins to facilitate their degradation by the proteasome. P97 works in different cellular processes using alternative sets of cofactors and is implicated in multiple degenerative diseases. Ubiquitin regulatory $X$ domain protein 1 (UBXD1) has been linked to pathogenesis and is unique amongst p97 cofactors because it interacts with both termini of p97. Its N-domain binds to the N-domain and N/D1 interface of p97 and regulates its ATPase activity. The PUB (peptide: $N$-glycanase and UBA or UBX-containing proteins) domain binds the p97 C-terminus, but how it controls p97 function is still unknown. Here we present the NMR structure of UBXD1-PUB together with binding studies, mutational analysis, and a model of UBXD1-PUB in complex with the p97 C-terminus. While the binding pocket is conserved among PUB domains, UBXD1-PUB features a unique loop and turn regions suggesting a role in coordinating interaction with downstream regulators and substrate processing
\end{abstract}

Keywords: UBXD1; p97/VCP/Cdc48; PUB domain; NMR structure; protein-protein interaction

\section{Introduction}

The ubiquitin proteasome system (UPS) critically regulates various cellular stress response pathways including ER-associated degradation (ERAD), ribosomal quality control (RQC), DNA damage repair, and autophagy that ensure cellular and protein homeostasis. A key element of the UPS is the conserved AAA + ATPase p97 (also called Cdc48 or VCP for valosin-containing protein) that targets a subset of ubiquitin-modified substrate proteins, extracts them from cellular structures, and unfolds them to facilitate degradation in the proteasome [1-3].

p97 comprises a regulatory N-terminal domain, two AAA ATPase domains (D1 and D2) that form a stacked hexamer, and a short, disordered C-terminal region [4,5]. Protein unfolding is mediated by ATP-driven translocation of substrate proteins through the central channel of the hexamer [6-9]. The function and activity of p97 is regulated by a large number of cofactor proteins [10]. They include substrate adapters that bind at the $\mathrm{N}$-domain and assist insertion of the substrates into the D1 pore $[9,11]$ and also many regulatory proteins that modulate p97 activity in different cellular processes [10].

Depletion of p97 is lethal, and point mutations in p97 cause a degenerative disease in humans that features inclusion body myopathy (IBM), fronto-temporal dementia (FTD), amyotrophic lateral sclerosis 
(ALS), and Paget's disease (PD) of bone (collectively called IBMPFD/ALS) [12]. Most disease-associated mutations are located at the interface between the $\mathrm{N}$ and D1 domains [13]. They affect cofactor binding, including the interaction with the UBXD1 cofactor, suggesting a link to pathogenesis [14,15]. UBXD1 is involved in p97-mediated functions in autophagy of damaged lysosomes and mitochondria as well as in WNT signaling [16-18]. Of note, UBXD1 is unique amongst the p97 cofactors because it is able to interact with both termini of p97 [19]. The N-terminus of UBXD1 includes a VCP-interacting motif (VIM) and additional elements that bind to the N/D1 interface of p97 [20,21]. This interaction regulates p97 ATPase activity by modulating the up/down mobility of the p97-N domain, and this regulation is affected by disease mutations [21,22].

Like many p97 cofactors, UBXD1 also possesses a C-terminal ubiquitin regulatory X(UBX) domain, which, however, lacks a critical FP motif and does not contribute to p97 binding [23]. Instead, the second element of the two-pronged interaction mechanism is a PUB (peptide: $N$-glycanase and UBA or UBX-containing proteins) domain [24], which binds the C-terminal tail of p97, possibly close to the D2 pore where unfolded proteins exit the central channel of p97. So far, the implications of this domain in substrate processing and its implication in disease pathogenesis are unknown.

PUB domains have been found in several proteins associated with the UPS that often also contain ubiquitin-associated (UBA) or UBX domains. The PUB domains were first considered as p97 binding modules $[23,25,26]$, but since the HOIL-1-interacting protein (HOIP/RNF31) also uses its PUB domain to interact with the OTU deubiquitinase with linear linkage specificity (OTULIN) and spermatogenesis-associated protein 2 (SPATA2) [27,28], PUB domains adopt a broader function within the UPS. Peptide N-glycanase (PNGase) binds to the PUB interacting motif (PIM) in the p97 C-terminus via its PUB domain and removes $\mathrm{N}$-linked oligosaccharide chains from misfolded glycoproteins prior to their degradation by the proteasome [29-31]. The E3 ubiquitin ligase HOIP/RNF31 associates with the proteins HOIL-1 and SHARPIN to form the linear ubiquitin assembly complex (LUBAC) which attaches linear M1-linked ubiquitin chains to its substrates and regulates inflammation via the NF- $k B$ pathway [32-34]. The LUBAC is regulated by the linear, chain-specific deubiquitinases OTULIN and CYLD. OTULIN contains a PIM sequence and is bound directly by HOIP-PUB [35,36]. CYLD, however, does not interact directly with HOIP, but via the adaptor protein SPATA2 [28,37]. SPATA2 contains both a PIM sequence, which is tightly bound by HOIP-PUB, and also a PUB domain on its own, which cannot bind a canonical PIM sequence but was found to interact with the ubiquitin-specific protease (USP) domain of CYLD [28,37]. Furthermore, HOIP also binds the p97 PIM, albeit with lesser affinity, and has been shown via co-immunoprecipitation/mass spectrometry experiments to interact with p97 in cells [34]. While p97 has also been associated with the NF-kB pathway [38,39], it is still not clear whether it is recruited via its interaction with HOIP [34].

While a few structures of other PUB domains are known [25,27-29,34] and conserved residues involved in PIM binding have been identified, the interesting question lies in the differences between homologous domains, which will lead the way to understand their functional role in the downstream processing of p97 substrates.

Here we present the solution structure of the UBXD1-PUB domain together with binding studies, mutational analysis, and a model of the UBXD1-PUB/p97-C complex. The structure of the UBXD1-PUB domain sheds light onto differences to other PUB domains and serves as an important building block to further understand the unique role of UBXD1 and its interaction with p97.

\section{Materials and Methods}

\subsection{Cloning, Protein Expression, and Purification}

N-terminal hexahistidine-tagged UBXD1-PUB (150-264) was cloned into a pET28a expression vector using the NdeI and HindIII restriction sites. UBXD1 point mutants were produced by site-directed mutagenesis following the Quikchange protocol (Agilent Technologies). All primer sequences are listed in Table S1. 
In short, all proteins were expressed in Escherichia coli Rosetta2 in M9 minimal media with 50 $\mu \mathrm{g} / \mathrm{mL}$ kanamycin and $30 \mu \mathrm{g} / \mathrm{mL}$ chloramphenicol and purified on a nickel-NTA affinity column followed by size exclusion chromatography after thrombin cleavage of the tag.

For the expression of unlabeled protein, $50 \mathrm{~mL}$ of an overnight culture in $\mathrm{M} 9$ minimal media was harvested, resuspended in $1 \mathrm{~L}$ M9 medium, and grown up to $\mathrm{OD}_{600}=1.0$ at $37^{\circ} \mathrm{C}, 160 \mathrm{rpm}$. For the expressions of ${ }^{15} \mathrm{~N}$ or ${ }^{13} \mathrm{C}_{1}^{15} \mathrm{~N}$ isotopically labeled protein, $11 \mathrm{M} 9$ minimal medium supplemented with $0.6 \mathrm{~g} / \mathrm{L}\left({ }^{15} \mathrm{~N}\right)$ ammonium sulfate and, for ${ }^{13} \mathrm{C}_{,}^{15} \mathrm{~N}$ labeling, $3 \mathrm{~g} / \mathrm{L}\left({ }^{13} \mathrm{C}\right)$ glucose were used and grown up to $\mathrm{OD}_{600}=1.0$. After induction of protein expression with $0.1 \mathrm{mM}$ Isopropyl- $\beta$-D-thiogalactopyranosid (IPTG), cells were incubated for $4 \mathrm{~h}$ at $37^{\circ} \mathrm{C}$ followed by centrifugation $\left(4000 \mathrm{rpm}, 20 \mathrm{~min}, 4{ }^{\circ} \mathrm{C}\right)$. Pelleted cells were dissolved in PBS buffer, $\mathrm{pH}$ 7.4, supplemented with 1 mM PMSF, and lysed with lysozyme $(1 \mathrm{mg} / \mathrm{mL})$ in combination with sonication. Upon ultracentrifugation $(35,000 \mathrm{rpm}, 60 \mathrm{~min}$, $4{ }^{\circ} \mathrm{C}$ ) to clear the lysate, the protein was purified by Ni-NTA affinity chromatography with PBS buffer, $\mathrm{pH} 7.4$, and eluted with an imidazole gradient. The $\mathrm{His}_{6}$ tag was cleaved with thrombin protease prior to size exclusion chromatography in $50 \mathrm{mM}$ sodium potassium phosphate, $150 \mathrm{mM}$ sodium chloride, $\mathrm{pH}$ 6.5. The protein was concentrated, and the buffer exchanged to sodium potassium phosphate buffer (50 mM NaKP $\mathrm{i}, \mathrm{pH} 6.5$ ), using a centrifugal concentrator (Vivaspin) with a $5 \mathrm{kDa}$ molecular weight cutoff. To the NMR samples in $\mathrm{H}_{2} \mathrm{O}, 10 \% \mathrm{D}_{2} \mathrm{O}$ was added. To prepare NMR samples in $100 \%$ $\mathrm{D}_{2} \mathrm{O}$, the protein in buffer was lyophilized and resuspended in $100 \% \mathrm{D}_{2} \mathrm{O}$. The molecular weight of the protein was confirmed by MALDI-MS.

\subsection{Peptides}

Unlabeled p97-C10 (TEDNDDDLYG), p97-C13 (SVYTEDNDDDLYG), and phosphorylated p97-C13 (SVYTEDNDDDLpYG) peptides for NMR and ITC as well as 5,6-FAM-labeled peptides for fluorescence studies were purchased from Caslo ApS (Denmark).

\subsection{Circular Dichroism (CD) Spectroscopy}

CD spectra were recorded on a Jasco J-170 CD spectrometer in a $1 \mathrm{~mm}$ quartz cuvette at $25^{\circ} \mathrm{C}$ averaging 25 scans. Samples consisted of $0.15 \mathrm{mg} / \mathrm{mL}$ protein in $50 \mathrm{mM} \mathrm{NaKPi}, \mathrm{pH}$ 6.5. The secondary structure composition was analyzed using DichroWeb (http://dichroweb.cryst.bbk.ac.uk) employing the CDSSTR algorithm $[40,41]$.

\subsection{MALDI-TOF Mass Spectrometry}

Samples for MALDI-TOF-MS were desalted using C18-pipette tips (Supelco) according to the manufacturer's protocol and mixed with a matrix containing 2,5-dihydroxyacetone (2,5-DHAP) and diammoniumhydrogencitrate (DAC). MALDI-MS spectra were measured with a Bruker Autoflex speed mass spectrometer, resulting in the measured mass of $13.84 \mathrm{kDa}\left(\mathrm{M}+\mathrm{K}^{+}\right.$; theoretical $\left.\mathrm{MW}=13.80 \mathrm{kDa}\right)$.

\subsection{Nuclear Magnetic Resonance (NMR) Spectroscopy}

The NMR samples contained $200-800 \mu \mathrm{M}$ of ${ }^{15} \mathrm{~N},{ }^{13} \mathrm{C}$ - or ${ }^{15} \mathrm{~N}$-labeled protein in $50 \mathrm{mM} \mathrm{NaKP} \mathrm{i}_{\mathrm{i}}$ $\mathrm{pH} 6.5,90 \% / 10 \%(\mathrm{v} / \mathrm{v}) \mathrm{H}_{2} \mathrm{O} / \mathrm{D}_{2} \mathrm{O} .{ }^{13} \mathrm{C}$ (aliphatic)-COSY and TOCSY experiments were measured in the same buffer with $100 \% \mathrm{D}_{2} \mathrm{O}$. All spectra were recorded at $25^{\circ} \mathrm{C}$ on a $700 \mathrm{MHz}$ Bruker Ultrashield NMR spectrometer equipped with a $5 \mathrm{~mm} \mathrm{TCI}\left({ }^{1} \mathrm{H} /{ }^{13} \mathrm{C} /{ }^{15} \mathrm{~N}\right)$ triple resonance cryoprobe head. Spectra were processed with Topspin 3.5 (Bruker) and analyzed with CARA [42].

\subsubsection{NMR Assignments}

Backbone assignments of ${ }^{15} \mathrm{~N},{ }^{13} \mathrm{C}$-PUB were accomplished using classical triple-resonance experiments [43]. Side chain assignments were based on 3D $\mathrm{H}(\mathrm{CCCO}) \mathrm{NH}, \mathrm{CC}(\mathrm{CO}) \mathrm{NH}$, as well as $3 \mathrm{D}$ aliphatic $\mathrm{HC}(\mathrm{C}) \mathrm{H}-\mathrm{COSY}$ and ${ }^{13} \mathrm{C}$ (aliphatic)- and ${ }^{13} \mathrm{C}$ (aromatic)-resolved $\mathrm{HC}(\mathrm{C}) \mathrm{H}$-TOCSY (DIPSI3 mixing time $10.9 \mathrm{~ms}$ ) experiments. To assign the aromatic resonances 
a ${ }^{13} \mathrm{C}$ (aliphatic) ${ }^{13} \mathrm{C}$ (aromatic)-resolved HC(C)H-TOCSY [44] was recorded with a FLOPSY2 mixing time of $28.87 \mathrm{~ms}$. Interproton distance constraints were obtained from $3 \mathrm{D}^{15} \mathrm{~N}-,{ }^{13} \mathrm{C}$ (aliphatic)-, and ${ }^{13} \mathrm{C}$ (aromatic)-resolved NOESY spectra recorded with a mixing time of $100 \mathrm{~ms}$.

Protein chemical shifts were referenced to internal 2,2-dimethyl-2-silapentane-5-sulfonate sodium salt (DSS). The ${ }^{15} \mathrm{~N}$ and ${ }^{13} \mathrm{C}$ chemical shifts were referenced indirectly to DSS according to IUPAC recommendations [45].

\subsubsection{NMR Structure Calculation}

Torsion angle restrains were calculated with TALOS [46]. Hydrogen bond donors could not be derived from H/D-exchange NMR experiments because the proton exchange was too fast. Therefore, $\mathrm{H}$-bonds within secondary structure elements were derived from the chemical shift index (CSI) [47], dihedral angles obtained from TALOS, and a backbone structural model calculated from $C_{\alpha}$ and $C_{\beta}$ chemical shifts by CS-Rosetta [48]. The use of H-bond restraints improved the quality of the resulting structure. A structure calculation without $\mathrm{H}$-bond restraints was performed to ensure that no artificial bias was introduced.

NOESY peak picking, assignment, and the structure calculation was performed with the ATNOS/CANDID module of the UNIO 10 software [49-51] in conjunction with CYANA 3.98 [52]. The 20 conformers with the lowest residual CYANA target function values obtained from the seventh ATNOS/CANDID/CYANA cycle were subjected to energy minimization in a water shell with YASARA. After structure validation, 20 conformers were selected to represent the NMR structures, and the programs PyMol and UCSF Chimera [53] were used to analyze this ensemble of conformers.

The accession number for the apo structure of UBXD1-PUB reported in this paper is PDB \# 6SAP, and the NMR chemical shifts are available in the BMRB database under the accession number 27977. The coordinates of the model shown in Figure 4 are available on request.

Structure validation. The PSVS server (http://psus-1_5-dev.nesg.org) and the PDB validation server (https://validate-pdbe.wwpdb.org/validservice/) were used to analyze the stereochemical quality of the molecular structures.

\subsubsection{NMR Titration Experiments}

To $362 \mu \mathrm{M}{ }^{15} \mathrm{~N}$-labeled UBXD1-PUB, the $\mathrm{p} 97-\mathrm{C} 10$ or $\mathrm{p} 97-\mathrm{C} 13$ peptides were added stepwise to a final concentration of $1.1 \mathrm{mM}$. For the titration of the phosphorylated $\mathrm{p} 97-\mathrm{C} 13-\mathrm{p} \mathrm{Y}^{805}$ peptide to the PUB domain, the protein concentration was $270 \mu \mathrm{M}$, and the peptide was titrated to a final concentration of $1.2 \mathrm{mM}$. After each addition, the ${ }^{1} \mathrm{H},{ }^{15} \mathrm{~N}-\mathrm{HSQC}$ spectrum was recorded.

The chemical shift perturbation $\Delta \delta_{\text {total }}$ was calculated from the ${ }^{1} \mathrm{H}$ - and ${ }^{15} \mathrm{~N}$-shifts according to Equation (1) [54] using the spectra with no peptide and the highest concentration of peptide, where $\Delta \delta_{N}$ and $\Delta \delta_{\mathrm{H}}$ represent the chemical shift perturbation value of the amide nitrogen and proton, respectively:

$$
\Delta \delta_{\text {total }}=\sqrt{\left(\Delta \delta_{\mathrm{H}}\right)^{2}+\left(0.154 \cdot \Delta \delta_{\mathrm{N}}\right)^{2}}
$$

\subsection{4. ${ }^{15} \mathrm{~N}$ Relaxation Measurements}

Nitrogen $T_{1}, T_{2}$ and steady state heteronuclear NOE relaxation experiments for ${ }^{15} \mathrm{~N}-\mathrm{UBXD1}$-PUB were collected at $25^{\circ} \mathrm{C}$ using sensitivity-enhanced pulse programs [55]. $\mathrm{T}_{1}$ and $\mathrm{T}_{2}$ relaxation delay times ranged from 20 to 1400 and 10 to $190 \mathrm{~ms}$, respectively. The saturated and unsaturated heteronuclear NOE experiments were collected in an interleaved manner, and the ratio of signal intensities was calculated for each resonance. $\mathrm{T}_{1}$ and $\mathrm{T}_{2}$ were fitted to a monoexponential function [56] using GraphPad Prism 5.0. The rotational correlation time $\tau_{\mathrm{c}}$ for each residue was calculated from $T_{1} / T_{2}$ (with $v_{\mathrm{N}}=$ Larmor frequency of nitrogen) [57]:

$$
\tau_{\mathrm{c}}=\frac{1}{4 \cdot \pi \cdot v_{\mathrm{N}}} \cdot \sqrt{6 \cdot \frac{\mathrm{T}_{1}}{\mathrm{~T}_{2}}-7}
$$


The molecular weight (MW) in solution of $13.0 \mathrm{kDa}$ was obtained from the linear correlation between MW and $\tau_{\mathrm{c}}$ as determined by Rossi et al. [57] and the averaged $\tau_{\mathrm{c}}=7.9 \mathrm{~ns}$.

\subsection{Fluorescence Anisotropy}

Fluorescence anisotropy measurements (excitation: $495 \mathrm{~nm}$; emission $518 \mathrm{~nm}$ ) were carried out on a JASCO FP-8300 fluorescence spectrometer in $50 \mathrm{mM} \mathrm{NaKP}$, $\mathrm{pH} 6.5$ at $25^{\circ} \mathrm{C}$, titrating PUB constructs to 5,6-FAM labeled p97-C10 peptide $(100 \mathrm{nM})$. All titrations were performed in triplicate. Binding curves of the averaged data were fitted with GraphPad Prism 5.0 (GraphPad) using the quadratic binding equation for a one-site specific binding model:

$$
\mathrm{r}=\mathrm{r}_{0}+\mathrm{r}_{\max } \cdot \frac{\left(\mathrm{F}+\mathrm{x}+\mathrm{K}_{\mathrm{D}}\right)-\sqrt{\left(\mathrm{F}+\mathrm{x}+\mathrm{K}_{\mathrm{D}}\right)^{2}-4 \cdot \mathrm{x} \cdot \mathrm{F}}}{2 \cdot \mathrm{F}},
$$

with $\mathrm{r}=$ anisotropy, $\mathrm{r}_{0}=$ anisotropy without protein, $\mathrm{r}_{\max }=$ maximum anisotropy, $\mathrm{F}=$ fluorescent probe (labeled peptide or protein) concentration, $\mathrm{x}=$ titrant protein concentration, and $\mathrm{K}_{\mathrm{D}}=$ dissociation constant.

Data points are shown as means \pm standard deviation based on the three experiments. $K_{D}$ values are given as fit of the averaged data points \pm standard deviation of the fit.

\subsection{Isothermal Titration Calorimetry (ITC)}

ITC measurements were performed in triplicate with a MicroCal iTC2000 (Malvern Pananalytical). UBXD1-PUB $(100 \mu \mathrm{M})$ was titrated with $1 \mathrm{mM}$ of p97-C10 peptide in $50 \mathrm{mM}$ NaKPi buffer (pH 6.5) at $25^{\circ} \mathrm{C}$ in 40 steps with a volume of $0.5 \mu \mathrm{L}$ for the first 9 steps and $1.0 \mu \mathrm{L}$ for the remaining ones. The binding parameters were calculated using MicroCal Origin (OriginLab) by fitting the data to a single-site binding model, and the binding parameters were averaged, yielding $K_{D}=15 \pm 5 \mu \mathrm{M}$, a stoichiometry of $\mathrm{n}=1.1 \pm 0.2$, and the thermodynamic parameters $\Delta \mathrm{H}=-3255 \pm 483 \mathrm{cal} / \mathrm{mol}$ and $\Delta S=10 \mathrm{cal} / \mathrm{mol} / \mathrm{K}$.

\subsection{Alignment of PUB structures and RMSD Calculation}

The apo structures of the UBXD1, PNGase, HOIP, and SPATA2 PUB domains were aligned in PyMol with the cealign command, using the core PUB residues 153-261 for UBXD1, 14-107 for PNGase (pdb \# 2CCQ, [29]), 52-155 for HOIP (pdb \# 4OYJ, [27]), and 64-168 for SPATA2 (pdb \# 5LJM, [28]).

\subsection{Model of UBXD1-PUB/p97-PIM Complex}

The UBXD1-PUB model from the NMR ensemble with the most open PIM binding pocket (model \#14) was aligned with the PNGase-PUB structure in complex with the p97-C10 peptide (pdb \# 2HPL) in PyMol. In this orientation, the p97-PIM peptide from the PNGase complex structure was added to the UBXD1-PUB apo structure. The peptide comprises only the last 5 residues (D802-G806) because the preceding residues were disordered and, thus, not visible in the crystal structure [25]. The resulting UBXD1-PUB7p97-PIM model was then subjected to energy minimization in Yasara using the macro em_run.

\section{Results}

\subsection{NMR Solution Structure of UBXD1-PUB.}

The UBXD1-PUB domain was previously identified as functional p97 binding unit [19,29], and the construct ranging from residues 150-264 yielded a well-dispersed ${ }^{15} \mathrm{~N}-\mathrm{HSQC}$ spectrum (Figure 1A). The averaged rotational correlation time of $\tau_{\mathrm{c}}=7.9 \mathrm{~ns}$ is obtained from the ratio of the ${ }^{15} \mathrm{~N}$ longitudinal $\left(T_{1}\right)$ and transverse $\left(T_{2}\right)$ relaxation times of all amide resonances (Figure 1B). $\tau_{c}$ can be correlated to the molecular weight (MW) of the protein in solution and reveals whether a protein forms multimeric 
assemblies [57]. For UBXD1-PUB, this yielded a MW of $13.0 \mathrm{kDa}$, which corresponds to the size of a monomer. The ${ }^{15} \mathrm{~N}-\mathrm{HetNOE}$ experiment, which shows whether an amide is situated in a structured or flexible region of the protein, revealed that the whole domain, except one loop region between P229 and P236, was a rigid unit with little internal mobility (Figure 1B).
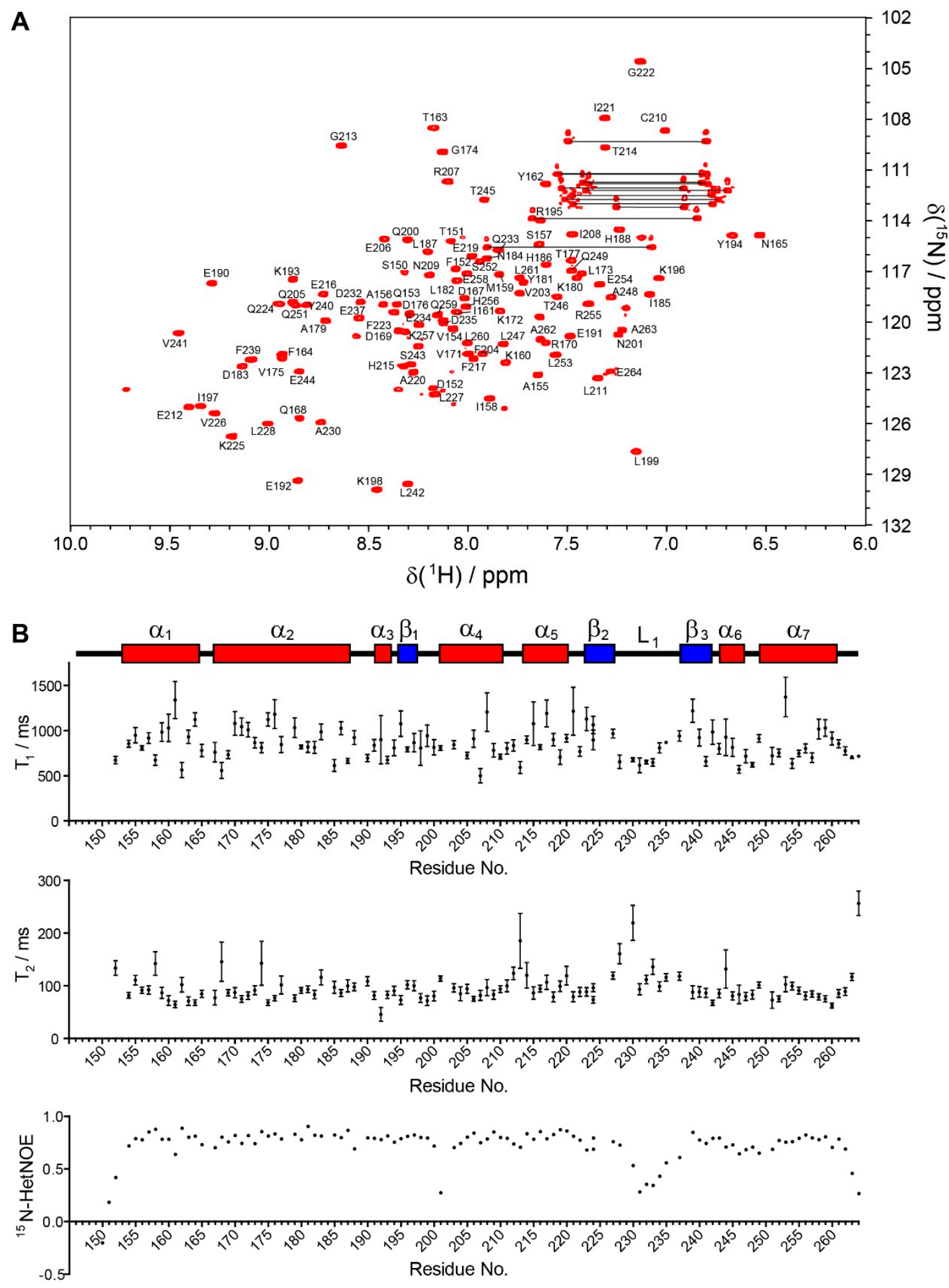

Figure 1. ${ }^{15} \mathrm{~N}-\mathrm{HSQC}$ spectrum and ${ }^{15} \mathrm{~N}$ relaxation data of UBXD1-PUB. (A) ${ }^{15} \mathrm{~N}-\mathrm{HSQC}$ spectrum with amide assignments; $(\mathbf{B}){ }^{15} \mathrm{~N}$ relaxation data (top: $\mathrm{T}_{1}$ relaxation times, middle: $\mathrm{T}_{2}$ relaxation times, bottom: ${ }^{15} \mathrm{~N}-\mathrm{HetNOE}$ ) plotted against the UBXD1-PUB sequence. Secondary structure elements are shown above. 
NMR assignments were obtained from 3D triple resonance and HCCH-COSY and -TOCSY spectra. ${ }^{13} \mathrm{C}$ and ${ }^{15} \mathrm{~N}$ NOESY spectra yielded 1221 distance constraints that, together with 567 dihedral angle constraints, were used to generate a bundle of the 20 lowest-energy conformers representing the NMR structure of UBXD1-PUB (Figure 2; for statistics see Table 1).

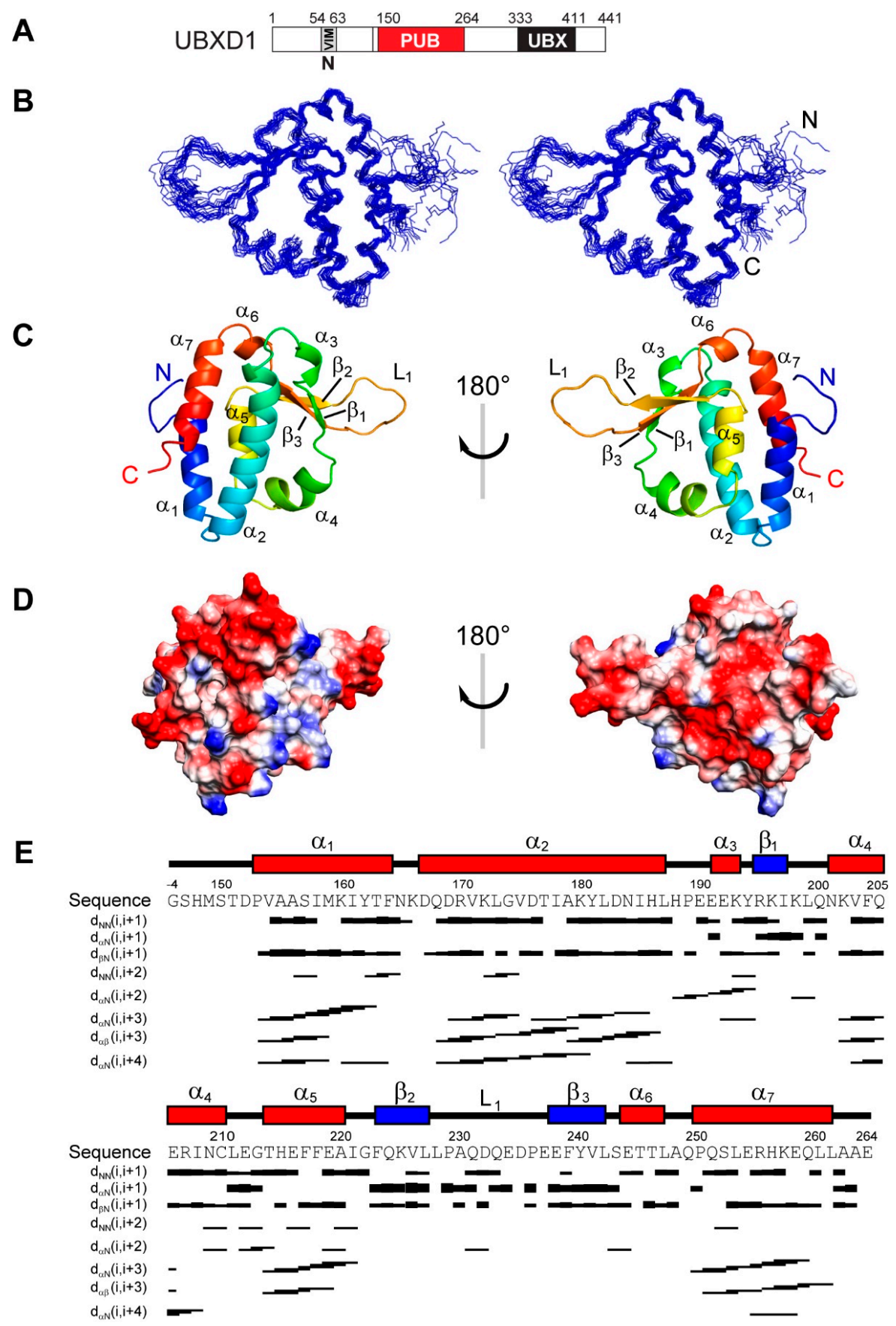

Figure 2. NMR structure of the UBXD1-PUB domain. (A) Schematic representation of UBXD1 with indication of the known functional domains. The UBXD1-PUB construct used in this study comprises residues 150-264; (B) bundle of 20 NMR conformers showing backbone atoms only in stereo view; (C) cartoon representation of the UBXD1-PUB domain, front and back view; (D) electrostatic charge distribution on the UBXD1-PUB domain, front and back view. Positively charged areas are shown in blue and negatively charged in red ( -8 to $+8 \mathrm{kcal} /(\mathrm{mol} \cdot \mathrm{e}))$; (E) NOE distribution chart. The UBXD1-PUB sequence and secondary structure elements are shown above. 
Table 1. Input for the structure calculation (constraints) and characterization of the ensembles of 20 energy-minimized CYANA conformers used to represent the NMR structure of UBXD1-PUB (150-264).

\begin{tabular}{|c|c|c|}
\hline Parameter & & Value \\
\hline Total structures computed & & 100 \\
\hline Number of structures analyzed & & 20 \\
\hline \multicolumn{3}{|l|}{ Constraints } \\
\hline \multicolumn{3}{|l|}{ NOE-based distance constraints } \\
\hline Total & & 1221 \\
\hline intra-residue $[\mathrm{i}=\mathrm{j}]$ & & 462 \\
\hline sequential $[|\mathrm{I}-\mathrm{j}|=1]$ & & 352 \\
\hline medium range $[1<|i-j|<5]$ & & 211 \\
\hline long range $[|\mathrm{i}-\mathrm{j}| \geq 5]$ & & 196 \\
\hline NOE constraints per restrained & & 10.3 \\
\hline \multicolumn{3}{|l|}{ residue } \\
\hline Dihedral angle constraints & & 567 \\
\hline Total \# of restricting constraints & & 1788 \\
\hline $\begin{array}{l}\text { Total \# of restricting constraints per } \\
\text { residue }\end{array}$ & & 15.0 \\
\hline $\begin{array}{l}\text { Restricting long-range constraints per } \\
\text { residue }\end{array}$ & & 1.6 \\
\hline \multicolumn{3}{|l|}{ Residual constraint violations ${ }^{a)}$} \\
\hline \multicolumn{3}{|l|}{ Distance violations / structure } \\
\hline $0.1-0.2 \AA$ & & 2.3 \\
\hline $0.2-0.5 \AA$ & & 0.2 \\
\hline$>0.5 \AA$ & & 0 \\
\hline RMS of distance violation / constraint & & $0.02 \AA$ \\
\hline Maximum distance violation & & $0.21 \AA$ \\
\hline \multicolumn{3}{|l|}{ Dihedral angle violations / structure } \\
\hline $1^{\circ}-10^{\circ}$ & & 2.6 \\
\hline$>10^{\circ}$ & & 1.05 \\
\hline $\begin{array}{l}\text { RMS of dihedral angle violation / } \\
\text { constraint }\end{array}$ & & $1.34^{\circ}$ \\
\hline Maximum dihedral angle violation & & $36.2^{\circ}$ \\
\hline \multicolumn{3}{|l|}{ RMSD to the mean structure } \\
\hline & all & ordered \\
\hline All backbone atoms & $1.6 \AA$ & $0.9 \AA$ \\
\hline All heavy atoms & $1.8 \AA$ & $1.3 \AA$ \\
\hline \multicolumn{3}{|l|}{ Ramachandran plot statistics ${ }^{b)}$} \\
\hline Most favored regions & & $85.9 \%$ \\
\hline Additionally allowed regions & & $13.3 \%$ \\
\hline Generously allowed regions & & $0.2 \%$ \\
\hline Disallowed regions & & $0.5 \%$ \\
\hline
\end{tabular}

a) after energy minimization with experimental constraints in Yasara. ${ }^{\text {b) }}$ from Procheck.

UBXD1-PUB consists of an antiparallel four-helix bundle comprising helices $\alpha_{1}$ (P153-F164), $\alpha_{2}$ (Q168-L187), $\alpha_{5}$ (T214-A220), and $\alpha_{7}$ (P250-L261). The $\beta$-strands $\beta_{1}$ (K196-L198), $\beta_{2}$ (F223-L227), and $\beta_{3}$ (E238-L242) form an antiparallel $\beta$-sheet packed against the helical bundle with an extended loop L1 (P229-P236) between strands $\beta_{2}$ and $\beta_{3}$. The short $3_{10}$-helix $\alpha_{3}$ (E192-E194) and $\alpha_{4}$ (K202-C210) together with sheet $\beta_{1}$ are part of the extended connection looping around between helices $\alpha_{2}$ and $\alpha_{5}$. The short helix $\alpha_{6}$ (E244-L247) connects sheet $\beta_{3}$ and the C-terminal helix $\alpha_{7}$. The overall structure shares high similarity with the core PUB fold of PNGase [25,29], which is also found in the PUB domains of HOIP [27,34] and SPATA2 [28]. HOIP and SPATA2, however, feature extended PUB domains with additional $\mathrm{N}$ - and/or C-terminal helices. In contrast to the other PUB domains, UBXD1-PUB displays the unique extended loop L1, which might be responsible for specific protein-protein interactions. 


\subsection{Interaction of UBXD1-PUB with p97-PIM.}

It was demonstrated previously that the UBXD1-PUB domain interacts with the unstructured C-terminal residues of p97 [19,27,29]. In our hands, isothermal titration calorimetry (ITC) experiments showed that the peptide comprising the last 10 residues of p97 (p97-C10) interacts with UBXD1-PUB with a $1: 1$ stoichiometry $(\mathrm{n}=1.1 \pm 0.2)$ and $\mathrm{K}_{\mathrm{D}}$ of $15 \pm 5 \mu \mathrm{M}, \Delta \mathrm{H}=-3255 \pm 483 \mathrm{cal} / \mathrm{mol}$, and $\Delta \mathrm{S}=10$ $\mathrm{cal} / \mathrm{mol} / \mathrm{K}$. The dissociation constant was confirmed by fluorescence anisotropy titrations $\left(\mathrm{K}_{\mathrm{D}}=14 \pm 1\right.$ $\mu \mathrm{M}$ ) and agreed with published values (Figure 3 and Figure 5C). This affinity was consistent with the $\mathrm{K}_{\mathrm{D}}$ value of $12 \mu \mathrm{M}$ reported by Elliot et al. [27] and was in the same low $\mu \mathrm{M}$ range as the affinities of homologous PUB domains for the p97-PIM peptide $[27,28]$.
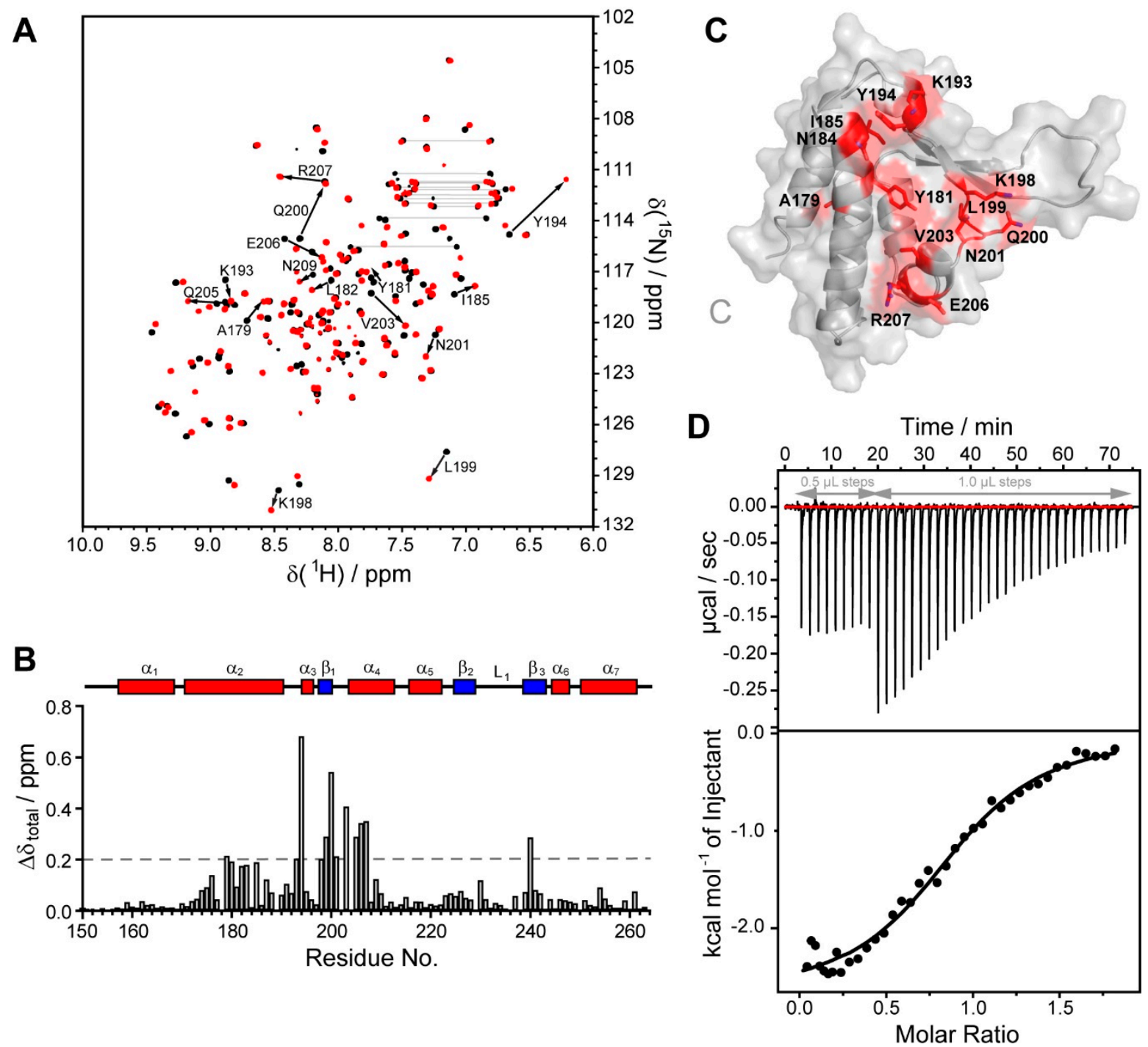

Figure 3. UBXD1-PUB binding to the p97 PIM motif. (A) ${ }^{15} \mathrm{~N}-\mathrm{HSQC}$ titration of ${ }^{15} \mathrm{~N}$-labeled UBXD1-PUB with p97-C10 PIM peptide. The spectrum in the absence of PIM is shown in black and the one in the presence of $1.1 \mathrm{mM}$ p97-PIM in red. Peaks shift during the titration, indicating intermediate-to-fast-exchange (see supplemental Figure S1 for full titration data). The residues experiencing the largest perturbations are labeled, and the signal shifts are indicated with an arrow; (B) chemical shift perturbations $\Delta \delta_{\text {total }}$ plotted against the UBXD1-PUB sequence. The dotted line represents the $\Delta \delta_{\text {total }}$ average. The secondary structure elements are shown above; (C) mapping of residues with larger-than-average shifts ( $>0.2 \mathrm{ppm}$, highlighted in red) onto the UBXD1-PUB structure; (D) representative ITC experiment of p97-C10 peptide titrated to UBXD1-PUB wt. The initial titration steps were executed with a volume of $0.5 \mu \mathrm{L}$, all subsequent steps with $1 \mu \mathrm{L}$. 
${ }^{15} \mathrm{~N}-\mathrm{HSQC}$ NMR titrations are uniquely suited to determine the residues involved in the interaction. Titration of ${ }^{15}$ N-UBXD1-PUB with the p97-C10 and p97-C13 peptide showed large (>0.2 ppm) chemical shift perturbations (CSPs) of resonances assigned to amide groups residing in the region between the second and fourth $\alpha$-helix (Figure 3 and Figure S1). The interacting residues V175, A179, K180, Y181, L182, I185, L187, E191, K193, Y194, K198, L199, Q200, N201, V203, E206, R207, N209, A230, F239, E258, and L261 are mapped onto the PUB structure in Figure 3. Residues Y181, L182, I185, Y 194, and I197 form a hydrophobic pocket, which is conserved in the PUB family. In the crystal structures of PNGase [25] and HOIP [34] in complex with the p97-PIM peptide, this pocket accommodates the conserved Tyr residue within the PIM motif.

In contrast to the unmodified p97-PIM, the p97-C13 peptide carrying a phosphorylated pY805 did not show any binding in a ${ }^{15} \mathrm{~N}-\mathrm{HSQC}$ NMR titration up to a concentration of $1.25 \mathrm{mM}$ (Figure $\mathrm{S1B}$ ), which is consistent with phosphorylation of p97-Y805 also completely abolishing binding of the PNGase and HOIP PUB domains [25,34].

\subsection{Structural Model of the UBXD1-PUB/p97-PIM Complex.}

Since the PIM binding pocket is highly conserved amongst PUB domains [28,34], and the crystal structure of PNGase-PUB in complex with the p97-PIM is known, we calculated a model of the UBXD1-PUB/p97-PIM complex by aligning the proteins, adding the PIM peptide to the UBXD1-PUB apo structure and performing an energy minimization in silico. This resulted in a slight adjustment of a few side chains compared to the apo structure in order to fully open the binding pocket (Figure 4). Within the hydrophobic pocket, p97-Y805 is stabilized by face-to-edge stacking in between Y181 and Y194 as well as putative $\mathrm{H}$ bonds of its $\mathrm{OH}$ group to the backbone carbonyl of $\mathrm{Y} 181$ and the side chain of N184. The carboxyl terminus of p97-G806 is situated within $\mathrm{H}$ bonding distance to the side chain of N201. K198 does not contact the carboxyl group of p97-G806 in our model, but it maintains an intramolecular salt bridge to D232 within the L1 loop as observed in the apo structure. p97-L804 is cradled by Y181, V203, and the aliphatic portion of the K180 side chain. The overall positively charged rim of the binding pocket, including R207 as well as K180, K193, K196, K198, and K202 (Figure 4C), ensures not only binding of the C-terminal carboxylate but also electrostatic attraction to the numerous acidic residues ( ${ }^{796}$ TEDNDDDLYG ${ }^{806}$ ) within p97-C10.
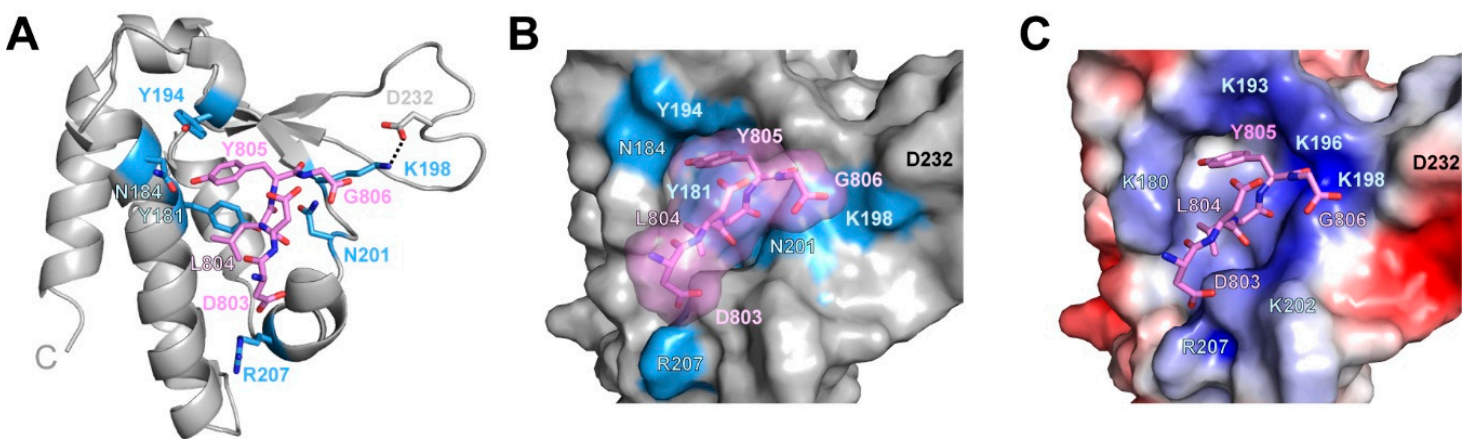

Figure 4. Model of the UBXD1-PUB/p97-PIM complex. (A) Energy-minimized model of the UBXD1-PUB/p97-PIM complex. UBXD1-PUB is shown as cartoon with the residues important for PIM binding highlighted as light blue sticks and the p97-PIM (residues 803-806) as pink sticks; (B) surface representation of the UBXD1 PIM binding pocket with bound p97-PIM. (C) Electrostatic charge distribution of the same view as in (B). Positively charged areas are shown in blue and negatively charged in red ( -4 to $+4 \mathrm{kcal} /(\mathrm{mol} \cdot \mathrm{e}))$. Positively charged PUB residues are labeled in light blue.

Overall, the PUB/p97-PIM complex is stabilized by a combination of hydrophobic and electrostatic interactions, with key interactions between the side chains of Y181, N184, and Y194 and the aromatic side chain of p97-Y805 inside a hydrophobic pocket of the PUB domain and binding of the free p97 C-terminus via $\mathrm{H}$ bonds and electrostatic interactions. 


\subsection{Structure-Based Mutational Analysis Confirms Conserved Binding Pocket.}

To evaluate the contribution of each residue to p97 binding, nine residues were selected for mutational analysis based on the NMR titration and the model of the UBXD1-PUB/p97-PIM complex. Correct folding of the mutants was confirmed using CD spectroscopy (Figure 5). The binding constants for each point mutant with p97-C10 were measured by fluorescence anisotropy (Table 2 and Figure S2). The largest decrease in binding affinity compared to the wild type PUB domain $\left(K_{D}=14 \pm 1 \mu \mathrm{M}\right)$ was observed for the mutants N201D, Y194F, and Y181A.

A

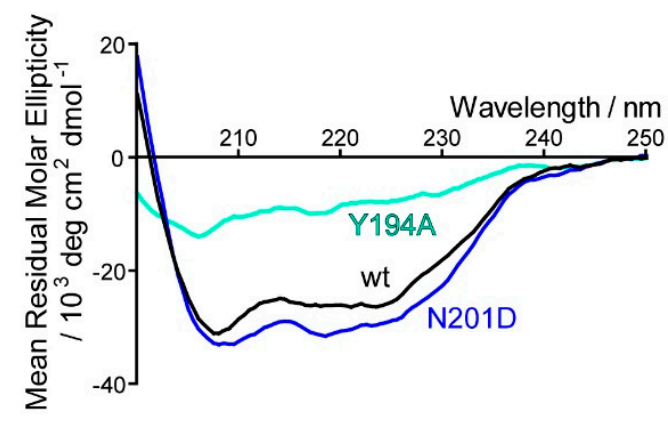

B

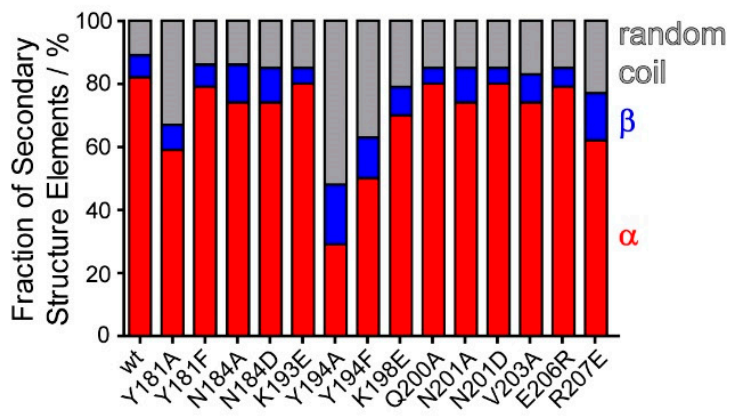

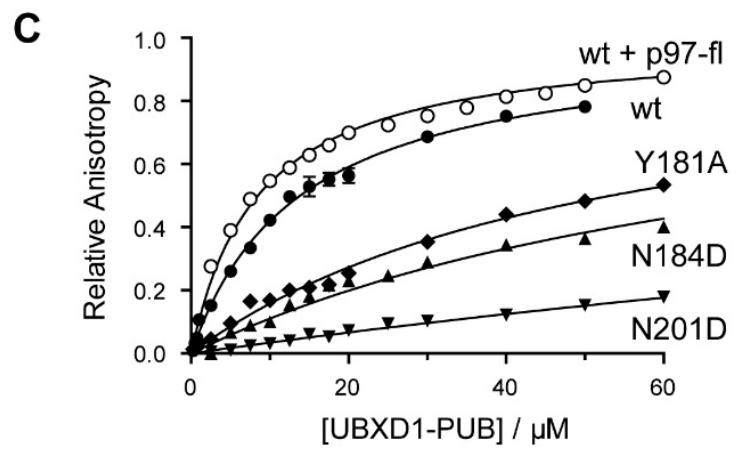

Figure 5. Mutational analysis of the UBXD1-PUB PIM binding pocket. (A) CD spectra of UBXD1-PUB wt and selected mutants; (B) secondary structure composition of UBXD1-PUB mutants obtained from deconvolution of the CD spectra with DichroWeb. The percentage of $\alpha$-helices is shown in red, $\beta$-sheets in blue, and random coil in gray. While most mutants remain folded with a secondary structure composition similar to the wild type, the Y194A mutant shows a partial loss of secondary structure. (C) Fluorescence anisotropy binding curves for selected UBXD1-PUB constructs with 5,6-FAM labeled p97-C10 peptide or full length p97. Error bars represent the standard deviation of three experiments. Only the concentration range up to $60 \mu \mathrm{M}$ is shown (for full titration data see Figure S2).

According to the model of the UBXD1-PUB/p97-PIM complex (Section 3.3 and Figure 4), N201 is involved in contacting the negatively charged C-terminal carboxylate of p97-G806. Thus, changing the neutral $\mathrm{N}$ to a negatively charged $\mathrm{D}$ results in electrostatic repulsion and a 20 -fold increase in $\mathrm{K}_{\mathrm{D}}$, while the corresponding N201A mutant, which lacks the ability to form a H-bond, shows a 5-fold higher $\mathrm{K}_{\mathrm{D}}$.

Both Tyr residues Y194 and Y181 are conserved and essential for the recognition of p97-Y805 [30]. Mutating $\mathrm{Y} 181$ to $\mathrm{A}\left(\mathrm{K}_{\mathrm{D}}=111 \pm 2 \mu \mathrm{M}\right)$ results in a much larger effect on p97 binding compared to the $\mathrm{F}$ mutant $\left(\mathrm{K}_{\mathrm{D}}=28.4 \pm 0.6 \mu \mathrm{M}\right)$, indicating that aromatic ring stacking is in fact crucial for the interaction, as predicted from our complex model (Figure 4). 
Table 2. Dissociation constants $\left(K_{D}\right)$ of UBXD1-PUB mutants with p97-C10 peptide or full-length p97 (p97-fl) determined by fluorescence anisotropy.

\begin{tabular}{cc}
\hline Mutant & $\mathbf{K}_{\mathbf{D}}(\boldsymbol{\mu M})$ \\
\hline wild type $(w t)$ & $13.8 \pm 0.3$ \\
Y181A & $111 \pm 2$ \\
Y181F & $28.4 \pm 0.6$ \\
N184A & $28.7 \pm 0.5$ \\
N184D & $80 \pm 2$ \\
K193E & $17.7 \pm 0.4$ \\
Y194A & $53 \pm 2$ \\
Y194F & $141 \pm 2$ \\
K198E & $49.3 \pm 0.8$ \\
Q200A & $8.3 \pm 0.3$ \\
N201A & $64.1 \pm 0.8$ \\
N201D & $280 \pm 3$ \\
V203A & $25.3 \pm 0.5$ \\
E206R & $39.4 \pm 0.9$ \\
R207E & $88 \pm 1$ \\
wt + p97-fl & $8.4 \pm 0.2$ \\
\hline
\end{tabular}

Both Y194F and Y194A mutations also result in a large decrease in affinity. However, since both mutations, especially Y194A, cause a decrease in $\alpha$-helical content revealed by their CD spectra (wt: 80\%, Y194A: 30\%, Y194F: 50\%), the absolute affinities have to be viewed with a grain of salt. The OH group of Y194 is situated in H bonding distance (2.9 $\AA$ ) to E191, which in turn is stabilized by an additional putative $H$ bond to $H 188$, in the loop region between helices $\alpha_{2}$ and $\alpha_{3}$, which might explain a destabilizing effect on the tertiary structure when it is removed (Figure 7 and Figure S3).

Mutating R207 to E results in a 6-fold decreased affinity, likely because this residue contacts one of the numerous aspartate residues within p97-C10. In contrast, K193E and Q200A do not show a decreased affinity compared to the wild type. Both their side chains face away from the binding pocket into the solvent; however, their amide groups are closer to the bound p97-C10, which explains the signal shifts observed in the NMR titrations.

\section{Discussion}

\subsection{Structural Homology between PUB Domains and Unique Features of UBXD1-PUB}

The UBXD1-PUB structure presented here (Figure 2) most closely resembles the PNGase PUB domain [29] $\left(C_{\alpha}\right.$-RMSD $\left.=2.01 \AA\right)$, which defines the canonical PUB fold consisting of an antiparallel four-helix bundle, a short three-stranded $\beta$-sheet, as well as a $3_{10}$-helix $\alpha_{3}$ and another short helix $\alpha_{4}$ framing the $\beta_{1}$ strand. The core PUB regions of HOIP (residues 52-155) and SPATA2 (residues 64-168) show a larger $C_{\alpha}$-RMSD of 3.42 or $4.09 \AA$, respectively.

UBXD1-PUB features a unique extended L1 loop between the strands $\beta_{2}$ and $\beta_{3}$, where the PUB domains of PNGase, HOIP, and SPATA2 only present a short turn (Figure 6). Further differences between PUB domains are located at the top of the four-helix bundle, where UBXD1-PUB exhibits an additional short helix $\alpha_{6}$. These unique structural features of UBXD1-PUB might indicate additional protein interaction sites with other components of p97- and UBXD1-mediated reactions (further discussion see below). 


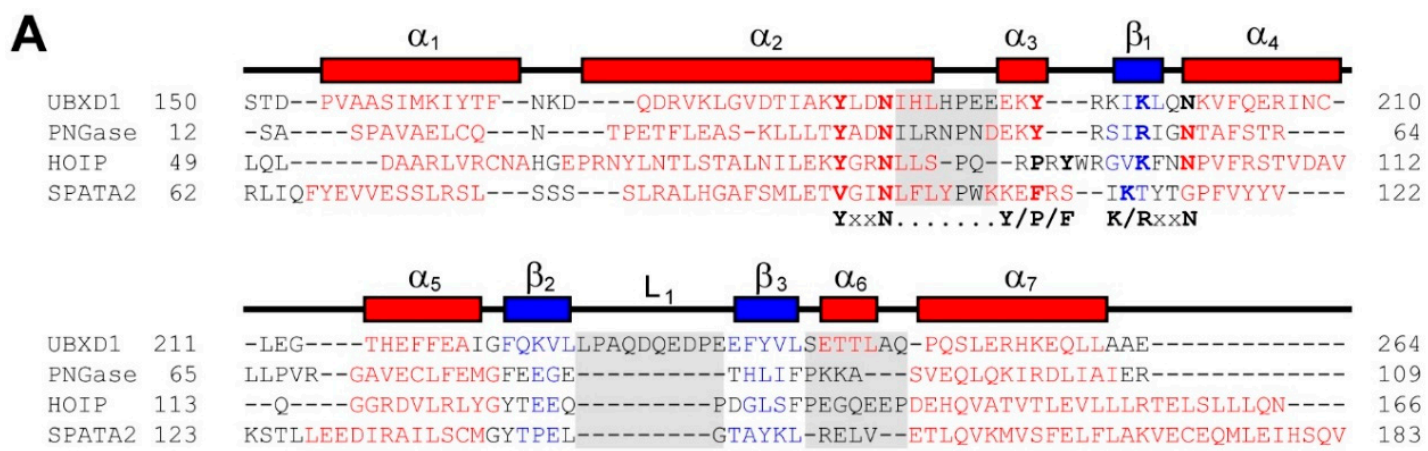

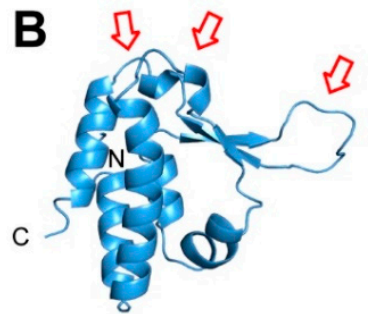

UBXD1

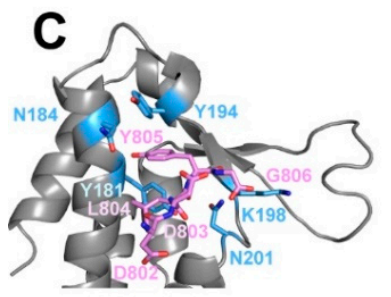

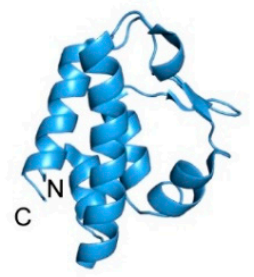

PNGase

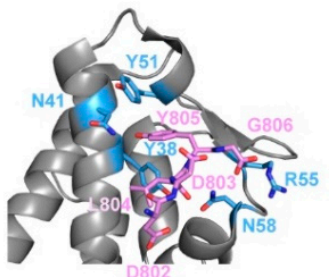

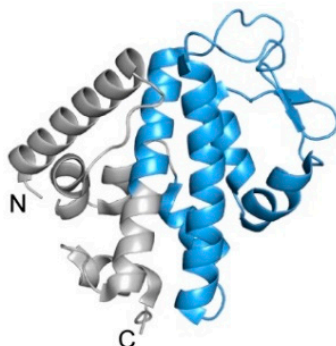

HOIP

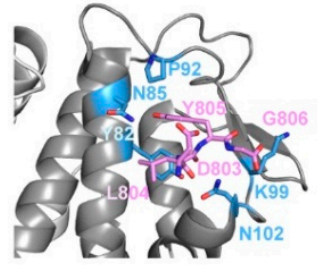

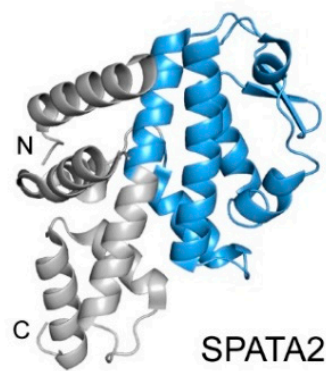

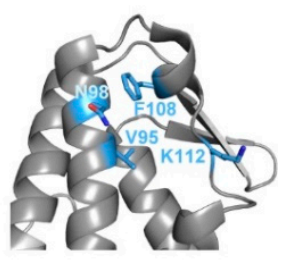

Figure 6. Comparison of UBXD1-PUB with other PUB domains. (A) Sequence alignment of UBXD1-PUB with the core PUB domains of human PNGase, HOIP, and SPATA2. The secondary structure of UBXD1-PUB is shown above (helices in red, $\beta$-sheets in blue). The conserved residues of the PIM pocket are in bold, and their motifs are labeled below. The loop and turn regions with the largest variability are highlighted with gray squares; (B) structural comparison of UBXD1-PUB with the PUB domains of PNGase (pdb \# 2CCQ, [29]), HOIP (pdb \# 4OYJ, [27]), and SPATA2 (pdb \# 5LJM, [28]). The core PUB fold is shown in blue and the extensions of HOIP and SPATA2 in gray. Red arrows highlight the places where UBXD1-PUB differs most from the PUB consensus (gray boxes in A); (C) close-up of the PIM pockets (light blue, sticks) of UBXD1, PNGase (pdb \# 2HPL, [25]) and HOIP (pdb \# 4P0A, [34]) in complex with the p97-PIM peptide (pink), and SPATA2 (apo, pdb \# 5LJM, [28]).

\subsection{Determinants of PIM Binding}

The hydrophobic PIM binding pocket of UBXD1-PUB (Figures 2 and 3) closely resembles the conserved $\Phi-\Psi$ pockets of PNGase and HOIP [25,27-29,34], which also bind canonical PIM sequences. The two conserved tyrosine residues (Y181 and Y194 in UBXD1) stack with the central PIM tyrosine (p97-Y805) in a face-to-edge manner. Furthermore, a conserved asparagine residue (UBXD1-N184) is in hydrogen bonding distance to the hydroxyl group of the PIM tyrosine. Taken together, this essential $\mathrm{YxxN}(\mathrm{x})_{9} \mathrm{Y}$ motif shared by UBXD1 and PNGase forms the core of the pocket, and mutation of any of these residues results in strongly impaired PIM binding.

The PIM binding pockets of UBXD1-PUB and its closest homologue PNGase-PUB and the position of the p97-PIM peptide inside the pocket are almost identical, with small differences (Figures 6 and 7). The side chains of the conserved UBXD1-Y181 and PNGase-Y38 are in the same position, stacking with p97-Y805 and forming a putative H-bond (3.2 or $3.1 \AA$, respectively) to the backbone carbonyl of p97-L804. UBDXD1-Y194 and PNGase-Y51, which represent the second conserved tyrosine of the PIM 
pocket, both stack with p97-Y805 and are only slightly shifted with respect to each other. However, the intramolecular interactions of this $Y$ within the respective PUB domain differ (Figure 7 and Figure S3). In contrast to PNGase-Y51, UBXD1-Y194 is involved in a potential hydrogen bonding network with the short loop between helices $\alpha_{2}$ and $\alpha_{3}$. In UBXD1, the OH group of Y194 lies in H bonding distance (2.9 $\AA$ ) to the carboxyl group of E191, which likely also forms an H bond to H188 (2.8 $)$. In place of UBXD1-E191, PNGase features D48 with a shorter side chain, which is also more turned away from the conserved tyrosine (Y51 in PNGase). PNGase-Y51 is placed slightly lower than UBXD1-Y194, increasing the distance to PNGase-D48 further. In addition, H188 in UBXD1 is replaced with N45 in PNGase, which is not in H bonding distance to PNGase-D48. This H bonding network, which is missing in PNGase, explains the local structural destabilization of the UBXD1-Y194 mutations observed in the CD spectrum and their moderate loss in PIM binding affinity. In contrast, the corresponding PNGase K50A, Y51A double mutant did not show impaired binding in a pulldown assay [29]; however, this assay is only qualitative in nature and does not reflect small changes in binding affinity.

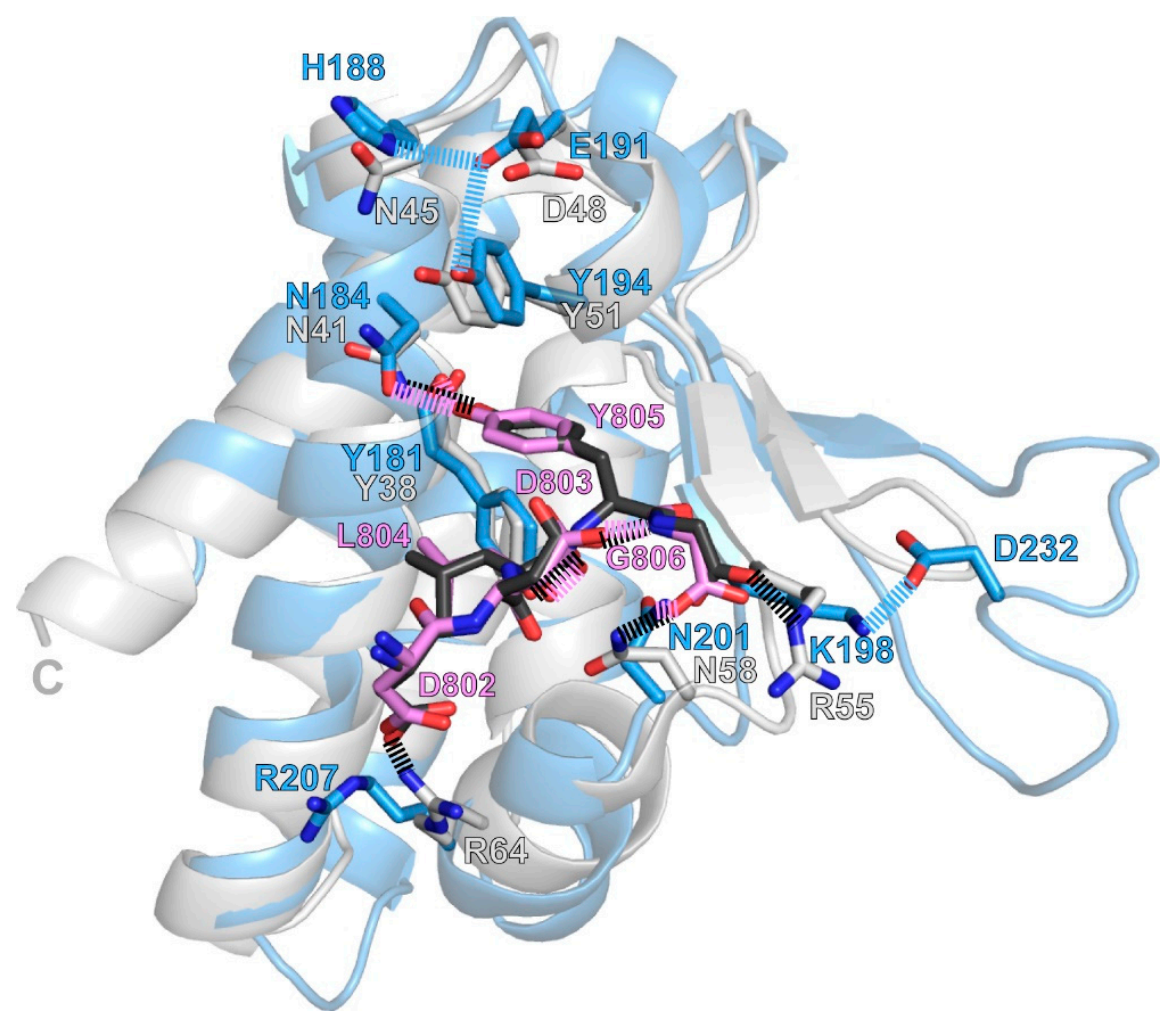

Figure 7. Comparison of the UBXD1-PUB/p97-PIM model with the PNGase/p97-PIM crystal structure (pdb \# 2HPL [25]). The model of UBXD1-PUB is shown in blue with the PIM peptide model in pink. PNGase-PUB is shown in gray with the bound p97-PIM peptide in black. Important residues are shown as sticks and labeled in the respective color of each protein. Residues of the p97-PIM peptide are labeled in pink. Potential intermolecular $\mathrm{H}$ bonds and salt bridges are shown as dashed lines in the color of the respective peptide. Intramolecular $\mathrm{H}$ bonds and salt bridges that are present in UBXD1-PUB but not PNGase-PUB are shown as blue dashed lines.

In PNGase-PUB, the $\mathrm{NH}_{2}$ group of the conserved $\mathrm{N} 41$ hydrogen bonds the $\mathrm{OH}$ group of $\mathrm{p} 97-\mathrm{Y} 805$ (2.8 $\AA$ ). In our UBXD1-PUB model, the corresponding N184 shows an alternate rotamer with the side chain carbonyl facing the $\mathrm{OH}$ group of p97-Y805, which possibly is an artifact because there were not sufficient NOE distance restraints to define the rotamer in the apo structure. This results in a larger potential $\mathrm{H}$ bond distance $(3.2 \AA)$ compared to the PNGase complex and brings the p97-Y805-OH group closer, and possibly into $\mathrm{H}$ bonding distance (3.2 $\AA$ ), to the backbone carbonyl of UBXD1-Y181 (Figure 7). The p97-L804 side chain is bound in an almost identical conformation in both complexes, in 
a hydrophobic pocket formed by the conserved UBXD1-Y181/PNGase-Y38 and the hydrophobic side chain portions of T177 and K180 in UBXD1 and L34 and T37 in PNGase.

A conserved asparagine (N201 in UBXD1 and N58 in PNGase) is in hydrogen bonding distance to the C-terminal carboxylate of p97-G806 in both protein complexes (2.9 $\AA$ in both complexes). Additionally, the C-terminal carboxylate of p97 is in close contact to the NHع atom of PNGase-R55, likely forming a salt bridge. Upon mutation of this residue, p97-PIM binding is completely abolished in PNGase-PUB [25]. In contrast, the corresponding K198 in the UBXD1 apo structure forms an intramolecular salt bridge to D232 situated in the L1 loop extension, not present in PNGase, which is still present in our complex model (Figures 6 and 7). Even though K198 is positioned such that it could possibly reach p97-G806 after a conformational change of its side chain and release of the contact to D232, it does not seem likely judging from the only moderate 3.5-fold effect on binding when this position is mutated in UBXD1-PUB.

Out of the stretch of negatively charged residues in p97-PIM, only two (D802 and D803) are visible in the PNGase/p97 complex crystal structure, with the remaining ones being disordered in the crystal; therefore, only these two aspartates are included in our model. In PNGase-PUB, R64 forms a potential salt bridge to p97-D802 (2.6 , Figure 7), while the corresponding R207 in our UBXD1-PUB complex model remains in a rotamer where it does not contact p97-D802. However, this could be a bias from the apo structure, and it is possible that R207 changes its conformation to contact p97-D802 on a time scale beyond our energy minimization. The six-fold reduction in binding affinity of the R207E mutant shows that this residue has some importance, but from our model it is not certain whether this is based on a direct contact to p97-D802 or on the overall positive electrostatic potential to which R207 contributes. The second p97 aspartate, D803, stabilizes the bound conformation of the p97 peptide in both complexes through a putative intramolecular $\mathrm{H}$ bond to the backbone amide HN of p97-G806 (Figure 7).

HOIP-PUB features a slightly different $\mathrm{YxxN}(\mathrm{x})_{6} \mathrm{PxY}$ motif where the $\mathrm{P}$ contacts the PIM tyrosine, which results in the p97-PIM sitting slightly higher in the pocket compared to UBXD1 and PNGase (Figure S4). The nearby $Y$ faces the PIM pocket in the apo structure, but is turned away in the structure of HOIP bound to p97-PIM. UBXD1, PNGase, and HOIP also share the K/RxxN motif (K198 and N201 in UBXD1), which binds the free C-terminal carboxylate of p97-G806. HOIP, however, can also bind the OTULIN- and SPATA2-PIMs, which are situated within the protein sequence. The overall positive surrounding of the PIM pocket serves to bind the negatively charged residues preceding the PIM tyrosine. Overall, the UBXD1 PIM pocket exhibits the conserved features also observed in PNGaseand HOIP-PUB. In contrast, SPATA2-PUB has not been found to bind a PIM sequence. The PIM pocket lacks the first conserved tyrosine, which is replaced by valine, and also shows a slightly different arrangement of the conserved residues. Instead, SPATA2-PUB binds the USP domain of CYLD, which dimerizes via its B-box and does not contain a PIM sequence [28].

UBXD1, PNGase, and HOIP PUB domains bind the p97-PIM peptide with $K_{D} s$ in the low $\mu \mathrm{M}$ range and a 1:1 stoichiometry (Table 2, Figure 4, Figure 5 and Figure $S 2$, and $[25,27,34]$ ). The $K_{D}$ of HOIP for the OTULIN- and SPATA2-PIMs, however, is 50 times lower and lies in the nM range, which maybe reflects that these complexes either operate at lower concentrations in the cell or a have a lesser need to exchange their binding partners. p97, on the other hand, might need to swap cofactors more readily either within one pathway or to switch between different pathways.

The affinities of the isolated PUB domains of UBXD1 (Table 2, Figure 3D) and PNGase for full-length p97 lie in the same range as for the isolated PIM peptides. While for the isolated PNGase-PUB with p97, a 1:1 stoichiometry has been found, and only two full-length PNGase can bind to one p97 hexamer [25], likely because of steric hindrance. In the case of UBXD1, at least in the endo-lysosomal damage response (ELDR), which regulates autophagy of lysosomes, it binds p97 concomitantly with another cofactor PLAA that also binds the p97 C-terminus [16], which also implies that not all PIM sites within the p97 hexamer are bound by UBXD1. 
Phosphorylation of p97-Y805 completely abolishes binding of the p97-PIM to UBXD1-PUB (Figure S1B), which has also been reported for the interactions of PNGase and HOIP with their respective PIM motifs [25,34]. This observation further supports the binding mode derived from our model (Section 3.3) where the $Y$ residue is inserted into a hydrophobic pocket and likely stabilized by aromatic stacking and $\mathrm{H}$ bonding interactions. The $\mathrm{Y}$ hydroxyl group is completely buried in this model. Phosphorylation at this position adds additional bulk that cannot be accommodated by the size of the pocket, and it also introduces a negative charge that cannot be stabilized in a hydrophobic environment. Most likely, phosphorylation of the conserved tyrosine within all PIM motifs serves a regulatory function so that the PUB-PIM interactions can be switched on or off (e.g., to regulate p97 activity during ERAD) [26].

\subsection{PUB Domains as Interaction Hubs in the Ubiquitin-Proteasome System}

PUB domains (Figure 6) bind to PIM-containing proteins like p97 and other members of the UPS via their conserved PIM-binding pocket, resulting in a modular assembly of these protein complexes. Binding is abolished upon PIM phosphorylation, which allows regulation of the protein degradation machinery in response to cellular damage [26]. Some PUB-containing proteins like PNGase have enzyme activity, opening up the possibility that they could process substrates emerging from the D2 pore of p97 after unfolding. However, UBXD1 lacks such activity and may execute a regulatory role.

Interestingly, the PUB domains of SPATA2 and PNGase show different or additional protein interaction modes: SPATA2 binds to the USP domain of the deubiquitinase CYLD involving residues of the PIM pocket, even though CYLD does not contain a PIM motif [28]. This interaction is dependent on the dimerization of CYLD through its B-box zinc finger domain [28].

The PIM pocket of SPATA2-PUB differs from the canonical pocket and does not bind any of the known PIM sequences, but it is involved in binding the PIM-less CYLD, indicating that this interaction follows an alternative mode that is not compatible with PIM binding at the same time. In contrast, the PNGase PUB domain can interact with the UBL domain of proteasome shuttle factor HR23 involving the turn between sheets $\beta_{2}$ and $\beta_{3}$ and the shorter helices $\alpha_{3}$ and $\alpha_{4}$ (corresponding to loop L1 and helices $\alpha_{3}$ and $\alpha_{4}$ in UBXD1-PUB) [49]. This interaction mode leaves the PIM binding pocket available, thereupon Kamiya et al. [58] propose that p97-bound PNGase can bind, and thus activate, HR23 at the same time. These two examples suggest that PUB domains function not just as PIM motif-binding adapters but constitute protein interaction hubs within their respective Ub-processing complex that are important for complex assembly and its regulation. Thus, UBXD1, through its PUB domain, may have a key role in organizing interactions with additional proteins that act at the C-terminus of p97 downstream of substrate unfolding and, at the same time, functionally link this to regulation of p97-N-domain movements and ATPase activity though the second binding site in UBXD1. Alternatively, the PUB domain could possibly mediate intramolecular contacts in the context of full-length UBXD1, which might help to orchestrate the binding mode (just the N-terminus, just PUB, or both) of UBXD1 to p97 in a temporal fashion during the p97 ATPase cycle or depending on the presence or absence of other cofactors. Our structure of the UBXD1-PUB domain may now help with further work to unravel the interaction network and understand its relevance for disease pathogenesis.

Supplementary Materials: The following are available online at http://www.mdpi.com/2218-273X/9/12/876/s1, Figure S1: ${ }^{15} \mathrm{~N}-\mathrm{HSQC}$ titrations of ${ }^{15} \mathrm{~N}-U B X D 1-P U B$ with the p97-C10 or the phosphorylated p97-C13 peptide. Figure S2: Fluorescence anisotropy titrations for all UBXD1-PUB mutants. Figure S3: Superposition of UBXD1-PUB and PNGase-PUB apo structures showing the H-bonding network of UBXD1-Y194. Figure S4: Superposition of the UBXD1-PUB/p97-PIM model and the crystal structures of PNGase and HOIP in complex with p97-PIM showing the position of the PIM peptide. Table S1: Oligonucleotides used as primers for PCR-amplification of the UBXD1-PUB (150-264) construct and for site-directed mutagenesis following the Quikchange protocol.

Author Contributions: Conceptualization, C.B., P.B., and H.M.; funding acquisition, P.B. and H.M.; investigation, M.B, C.B., and J.v.d.B.; formal analysis, C.B.; resources, H.M. and P.B.; supervision, C.B. and P.B.; writing-original draft, M.B. and C.B.; Writing-reviewing \& editing, P.B., H.M., and C.B.

Funding: This research was funded by DFG (Deutsche Forschungsgemeinschaft) for the research within CRC 1093. 
Acknowledgments: We thank T. Gerdes, A. Rute, and P. Binz for technical support, K. Schweimer for the ${ }^{13} \mathrm{C}$-NOESY pulse sequences, and T. Herrmann for UNIO trouble shooting. This research was funded by the CRC 1093 of the DFG (Deutsche Forschungsgemeinschaft).

Conflicts of Interest: The authors declare no conflicts of interest.

\section{References}

1. Ye, Y.; Tang, W.K.; Zhang, T.; Xia, D. A Mighty "Protein Extractor" of the Cell: Structure and Function of the p97/CDC48 ATPase. Front. Mol. Biosci. 2017, 4, 39. [CrossRef] [PubMed]

2. van den Boom, J.; Meyer, H. VCP/p97-Mediated Unfolding as a Principle in Protein Homeostasis and Signaling. Mol. Cell 2018, 69, 182-194. [CrossRef] [PubMed]

3. Stach, L.; Freemont, P.S. The AAA+ ATPase p97, a cellular multitool. Biochem. J. 2017, 474, $2953-2976$. [CrossRef] [PubMed]

4. Zhang, X.; Shaw, A.; Bates, P.A.; Newman, R.H.; Gowen, B.; Orlova, E.; Gorman, M.A.; Kondo, H.; Dokumo, P.; Lally, J.; et al. Structure of the AAA ATPase p97. Mol. Cell 2000, 6, 1473-1484. [CrossRef]

5. Davies, J.M.; Brunger, A.T.; Weis, W.I. Improved Structures of Full-Length p97, an AAA ATPase: Implications for Mechanisms of Nucleotide-Dependent Conformational Change. Structure 2008, 16, 715-726. [CrossRef] [PubMed]

6. Blythe, E.E.; Olson, K.C.; Chau, V.; Deshaies, R.J. Ubiquitin- and ATP-dependent unfoldase activity of P97/VCP•NPLOC4•UFD1L is enhanced by a mutation that causes multisystem Proteinopathy. Proc. Natl. Acad. Sci. USA 2017, 114, E4380-E4388. [CrossRef] [PubMed]

7. Bodnar, N.O.; Rapoport, T.A. Molecular Mechanism of Substrate Processing by the Cdc48 ATPase Complex. Cell 2017, 169, 722-735. [CrossRef]

8. Cooney, I.; Han, H.; Stewart, M.G.; Carson, R.H.; Hansen, D.T.; Iwasa, J.H.; Price, J.C.; Hill, C.P.; Shen, P.S. Structure of the Cdc48 segregase in the act of unfolding an authentic substrate. Science 2019, 365, 502-505. [CrossRef]

9. Weith, M.; Seiler, J.; van den Boom, J.; Kracht, M.; Hülsmann, J.; Primorac, I.; Del Pino Garcia, J.; Kaschani, F.; Kaiser, M.; Musacchio, A.; et al. Ubiquitin-Independent Disassembly by a p97 AAA-ATPase Complex Drives PP1 Holoenzyme Formation. Mol. Cell 2018, 72, 766-777. [CrossRef]

10. Buchberger, A.; Schindelin, H.; Hänzelmann, P. Control of p97 function by cofactor binding. FEBS Lett. 2015, 589, 2578-2589. [CrossRef]

11. Twomey, E.C.; Ji, Z.; Wales, T.E.; Bodnar, N.O.; Ficarro, S.B.; Marto, J.A.; Engen, J.R.; Rapoport, T.A. Substrate Processing by the Cdc48 ATPase complex is initiated by ubiquitin unfolding. Science 2019, 365, eaax1033. [CrossRef] [PubMed]

12. Meyer, H.; Weihl, C.C. The VCP/p97 system at a glance: Connecting cellular function to disease pathogenesis. J. Cell Sci. 2014, 127, 3877-3883. [CrossRef] [PubMed]

13. Watts, G.D.; Wymer, J.; Kovach, M.J.; Mehta, S.G.; Mumm, S.; Darvish, D.; Pestronk, A.; Whyte, M.P.; Kimonis, V.E. Inclusion body myopathy associated with Paget disease of bone and frontotemporal dementia is caused by mutant valosin-containing protein. Nat. Genet. 2004, 36, 377-381. [CrossRef] [PubMed]

14. Fernández-Sáiz, V.; Buchberger, A. Imbalances in p97 co-factor interactions in human Proteinopathy. EMBO Rep. 2010, 11, 479-485. [CrossRef] [PubMed]

15. Ritz, D.; Vuk, M.; Kirchner, P.; Bug, M.; Schütz, S.; Hayer, A.; Bremer, S.; Lusk, C.; Baloh, R.H.; Lee, H.; et al. Endolysosomal sorting of ubiquitylated caveolin-1 is regulated by VCP and UBXD1 and impaired by VCP disease mutations. Nat. Cell Biol. 2011, 13, 1116-1123. [CrossRef] [PubMed]

16. Papadopoulos, C.; Kirchner, P.; Bug, M.; Grum, D.; Koerver, L.; Schulze, N.; Poehler, R.; Dressler, A.; Fengler, S.; Arhzaouy, K.; et al. VCP/p97 cooperates with YOD1, UBXD1 and PLAA to drive clearance of ruptured lysosomes by autophagy. EMBO J. 2017, 36, 135-150. [CrossRef]

17. Reim, G.; Hruzova, M.; Goetze, S.; Basler, K. Protection of armadillo/ $\beta$-Catenin by armless, a novel positive regulator of wingless signaling. PLoS Biol. 2014, 12, e1001988. [CrossRef]

18. Bento, A.C.; Bippes, C.C.; Kohler, C.; Hemion, C.; Frank, S.; Neutzner, A. UBXD1 is a mitochondrial recruitment factor for p97/VCP and promotes mitophagy. Sci. Rep. 2018, 8, 12415. [CrossRef]

19. Kern, M.; Fernandez-Sáiz, V.; Schäfer, Z.; Buchberger, A. UBXD1 binds p97 through two independent binding sites. Biochem. Biophys. Res. Commun. 2009, 380, 303-307. [CrossRef] 
20. Stapf, C.; Cartwrightm, E.; Bycroft, M.; Hofmann, K.; Buchberger, A. The general definition of the p97/valosin-containing protein (VCP)-interacting motif (VIM) delineates a new family of p97 cofactors. J. Biol. Chem. 2011, 286, 38670-38678. [CrossRef]

21. Trusch, F.; Matena, A.; Vuk, M.; Koerver, L.; Knævelsrud, H.; Freemont, P.S.; Meyer, H.; Bayer, P. The N-terminal Region of the Ubiquitin Regulatory X (UBX) Domain-containing Protein 1 (UBXD1) Modulates Interdomain Communication within the Valosin-containing Protein p97. J. Biol. Chem. 2015, 290, 29414-29427. [CrossRef] [PubMed]

22. Schuetz, A.K.; Kay, L.E. A Dynamic molecular basis for malfunction in disease mutants of p97/VCP. eLife 2016, 5, e20143. [CrossRef] [PubMed]

23. Madsen, L.; Andersen, K.M.; Prag, S.; Moos, T.; Semple, C.A.; Seeger, M.; Hartmann-Petersen, R. Ubxd1 is a novel co-factor of the human p97 ATPase. Int. J. Biochem. Cell Biol. 2008, 40, 2927-2942. [CrossRef] [PubMed]

24. Suzuki, T.; Park, H.; Till, E.A.; Lennarz, W.J. The PUB domain: A putative protein-protein interaction domain implicated in the ubiquitin-proteasome pathway. Biochem. Biophys. Res. Commun. 2001, 287, 1083-1087. [CrossRef] [PubMed]

25. Zhao, G.; Zhou, X.; Wang, L.; Li, G.; Schindelin, H.; Lennarz, W.J. Studies on peptide:N-glycanase-p97 interaction suggest that $\mathrm{p} 97$ phosphorylation modulates endoplasmic reticulum-associated degradation. Proc. Natl. Acad. Sci. USA 2007, 104, 8785-8790. [CrossRef]

26. Li, G.; Zhao, G.; Schindelin, H.; Lennarz, W.J. Tyrosine phosphorylation of ATPase p97 regulates its activity during ERAD. Biochem. Biophys. Res. Commun. 2008, 375, 247-251. [CrossRef]

27. Elliot, P.R.; Nielsen, S.V.; Marco-Casanove, P.; Fiil, B.K.; Keusekotten, K.; Mailand, N.; Freund, S.M.V.; Gyrd-Hansen, M.; Komander, D. Molecular Basis and Regulation of OTULIN-LUBAC Interaction. Mol. Cell 2014, 54, 335-348. [CrossRef]

28. Elliott, P.R.; Leske, D.; Hrdinka, M.; Bagola, K.; Fiil, B.K.; McLaughlin, S.H.; Wagstaff, J.; Volkmar, N.; Christianson, J.C.; Kessler, B.M.; et al. SPATA2 Links CYLD to LUBAC, Activates CYLD, and Controls LUBAC Signaling. Mol. Cell 2016, 63, 990-1005. [CrossRef]

29. Allen, M.D.; Buchberger, A.; Bycroft, M. The PUB domain functions as a p97 binding module in human peptide N-glycanase. J. Biol. Chem. 2006, 281, 25502-25508. [CrossRef]

30. Li, G.; Zhao, G.; Zhou, X.; Schindelin, H.; Lennarz, W. The AAA ATPase p97 links peptide N-glycanase to the endoplasmic reticulum-associated E3 ligase autocrine motility factor receptor. Proc. Natl. Acad. Sci. USA 2006, 103, 8348-8353. [CrossRef]

31. Hirsch, C.; Blom, D.; Ploegh, H.L. A role for N-glycanase in the cytosolic turnover of glycoproteins. EMBO J. 2003, 33, 1036-1046. [CrossRef]

32. Kirisako, T.; Kamei, K.; Murata, S.; Kato, M.; Fukumoto, H.; Kanie, M.; Sano, S.; Tokunaga, F.; Tanaka, K.; Iwai, K. A ubiquitin ligase complex assembles linear polyubiquitin chains. EMBO J. 2006, 25, 4877-4887. [CrossRef]

33. Walczak, H.; Iwai, K.; Dikic, I. Generation and physiological roles of linear ubiquitin chains. BMC Biol. 2012, 10, 23. [CrossRef]

34. Schaeffer, V.; Akutsu, M.; Olma, M.H.; Gomes, L.C.; Kawasaki, M.; Dikic, I. Binding of OTULIN to the PUB domain of HOIP controls NF-kB signaling. Mol. Cell 2014, 54, 349-361. [CrossRef]

35. Keusekotten, K.; Elliott, P.R.; Glockner, L.; Fiil, B.K.; Damgaard, R.B.; Kulathu, Y.; Wauer, T.; Hospenthal, M.K.; Gyrd-Hansen, M.; Krappmann, D.; et al. OTULIN antagonizes LUBAC signaling by specifically hydrolyzing Met1-linked polyubiquitin. Cell 2013, 153, 1312-1326. [CrossRef]

36. Rivkin, E.; Almeida, S.M.; Ceccarelli, D.F.; Juang, Y.-C.; MacLean, T.A.; Srikumar, T.; Huang, H.; Dunham, W.H.; Fukumura, R.; Xie, G.; et al. The linear ubiquitin-specific deubiquitinase gumby regulates angiogenesis. Nature 2013, 498, 318-324. [CrossRef]

37. Schlicher, L.; Brauns-Schubert, P.; Schubert, F.; Maurer, U. SPATA2: More than a missing link. Cell Death Differ. 2017, 24, 1142-1147. [CrossRef]

38. Custer, S.K.; Neumann, M.; Lu, H.; Wright, A.C.; Taylor, J.P. Transgenic mice expressing mutant forms $\mathrm{VCP} / \mathrm{p} 97$ recapitulate the full spectrum of IBMPFD including degeneration in muscle, brain and bone. Hum. Mol. Genet. 2010, 19, 1741-1755. [CrossRef]

39. Li, J.M.; Wu, H.; Zhang, W.; Blackburn, M.R.; Jin, J. The p97-UFD1L-NPL4 protein complex mediates cytokine-induced IkBa proteolysis. Mol. Cell. Biol. 2014, 34, 335-347. [CrossRef] 
40. Lobley, A.; Whitmore, L.; Wallace, B.A. DICHROWEB: An interactive website for the analysis of protein secondary structure from circular dichroism spectra. Bioinformatics 2002, 18, 211-212. [CrossRef]

41. Whitmore, L.; Wallace, B.A. DICHROWEB: An online server for protein secondary structure analyses from circular dichroism spectroscopic data. Nucleic Acids Res. 2004, 32, W668-W673. [CrossRef]

42. Keller, R. The Computer Aided Resonance Assignment Tutorial, 1st ed.; Cantina Verlag: Goldau, Switzerland, 2004; Available online: http://www.cara.nmr-software.org/downloads/3-85600-112-3.pdf (accessed on 6 August 2018).

43. Sattler, M.; Schleucher, J.; Griesinger, C. Heteronuclear multidimensional NMR experiments for the structure determination of proteins in solution employing pulsed field gradients. Prog. Nucl. Magn. Reson. Spectrosc. 1999, 34, 93-158. [CrossRef]

44. Kovacs, H.; Gossert, A. Improved NMR experiments with 13C-isotropic mixing for assignement of aromatic and aliphatic side chains in labeled proteins. J. Biomol. NMR 2014, 58, 101-112. [CrossRef]

45. Wishart, D.; Bigam, C.; Yao, J.; Abildgaard, F.; Dyson, H.; Oldfield, E.; Markley, J.; Sykes, B. 1H, 13C and 15N chemical shift referencing in biomolecular NMR. J. Biomol. NMR 1995, 6, 135-140. [CrossRef]

46. Cornilescu, G.; Delaglio, F.; Bax, A. Protein backbone angle restraints from searching a database for chemical shift and sequence homology. J. Biomol. NMR 1999, 13, 289-302. [CrossRef]

47. Wishart, D.S.; Sykes, B.D. The 13C Chemical-Shift Index: A simple method for the identification of protein secondary structure using 13C chemical-shift data. J. Biomol. NMR 1994, 4, 171-180. [CrossRef]

48. Shen, Y.; Vernon, R.; Baker, D.; Bax, A. De novo protein structure generation from incomplete chemical shift assignments. J. Biomol. NMR 2009, 43, 63-78. [CrossRef]

49. Serrano, P.; Pedrini, B.; Mohanty, B.; Geralt, M.; Herrmann, T.; Wüthrich, K. The J-UNIO protocol for automated protein structure determination by NMR in solution. J. Biomol. NMR 2012, 53, 341-354. [CrossRef]

50. Herrmann, T.; Güntert, P.; Wüthrich, K. Protein NMR structure determination with automated NOE identification in the NOESY spectra using the new software ATNOS. J. Biomol. NMR 2002, 24, 171-189. [CrossRef]

51. Herrmann, T.; Güntert, P.; Wüthrich, K. Protein NMR structure determination with automated NOE assignment using the new software CANDID and the torsion angle dynamics algorithm DYANA. J. Mol. Biol. 2002, 319, 209-227. [CrossRef]

52. Güntert, P. Automated NMR structure calculation with CYANA. Methods Mol. Biol. 2004, 278, 353-378.

53. Pettersen, E.; Goddard, T.; Huang, C.; Couch, G.; Greenblatt, D.; Meng, E.; Ferrin, T. UCSF Chimera-A visualization system for exploratory research and analysis. J. Comput. Chem. 2004, 25, 1605-1612. [CrossRef]

54. Ayed, A.; Mulder, F.A.; Yi, G.S.; Lu, Y.; Kay, L.E.; Arrowsmith, C.H. Latent and active p53 are identical in conformation. Nat. Struct. Biol. 2001, 8, 756-760. [CrossRef]

55. Farrow, N.A.; Muhandiram, R.; Singer, A.U.; Pascal, S.M.; Kay, C.M.; Gish, G.; Shoelson, S.E.; Pawson, T.; Forman-Kay, J.D.; Kay, L.E. Backbone Dynamics of a Free and a Phosphopeptide-Complexed Src Homology 2 Domain Studied by 15N NMR Relaxation. Biochemistry 1994, 33, 5984-6003. [CrossRef]

56. Kay, L.E.; Nicholson, L.K.; Delaglio, F.; Bax, A.; Torchia, D.A. Pulse sequences for removal of the effects of cross correlation between dipolar and chemical-shift anisotropy relaxation mechanisms on the measurement of heteronuclear T1 and T2 values in proteins. J. Magn. Reson. 1992, 97, 359-375. [CrossRef]

57. Rossi, P.; Swapna, G.V.; Huang, Y.J.; Aramini, J.M.; Anklin, C.; Conover, K.; Hamilton, K.; Xiao, R.; Acton, T.B.; Ertekin, A.; et al. A microscale protein NMR sample screening pipeline. J. Biomol. NMR 2010, 46, 11-22. [CrossRef]

58. Kamiya, Y.; Uekusa, Y.; Sumiyoshi, A.; Sasakawa, H.; Hirao, T.; Suzuki, T.; Kato, K. NMR characterization of the interaction between the PUB domain of peptide:N-glycanase and ubiquitin-like domain of HR23. FEBS Lett. 2012, 586, 1141-1146. [CrossRef]

(C) 2019 by the authors. Licensee MDPI, Basel, Switzerland. This article is an open access article distributed under the terms and conditions of the Creative Commons Attribution (CC BY) license (http://creativecommons.org/licenses/by/4.0/). 